\title{
Tycho and the ton of gold
}

\section{Why a brilliantly conceived research programme failed.}

\section{Owen Gingerich}

$\mathrm{T}$ ycho Brahe is widely known as the eccentric sixteenth-century Danish nobleman with the silver nose, the egotistic builder of a battery of pre-telescopic astronomical instruments, and the observer whose precious and refined data on Mars made possible Johannes Kepler's discovery of the elliptical orbits of the planets.

Tycho boasted that his observations on the small island of Hven had cost the King of Denmark more than a ton of gold. The gold bought an array of quadrants, sextants and armillary spheres, with which he could measure an accuracy of one minute of arc, essentially the limit of the naked eye. Tycho never published the great bulk of his observations, nor his rationale for making many of them.

In our world of publish or perish, an understanding of what drove Tycho has nearly perished, leaving only a caricature of one of the most brilliant experimentalists of the past millennium. Had the dimensions of the Solar System been as small as everyone from the ancient Greeks onwards had assumed, Tycho would be known as the towering observational cosmologist who was the first to demonstrate that Ptolemy's geocentric arrangement of the planets was untenable.

In 1572, a spectacular new star appeared in the constellation Cassiopeia, what would be recognized today as a supernova. Tycho promptly discovered that this star showed no diurnal parallax, the small angular displacement that depends on where from the Earth the observation is made. For the Moon, the parallactic angle is about a degree; since the nova's was much less than this, the new star had to be much farther away than the Moon. This placed it in the supposedly unchanging and incorruptible celestial regions of the cosmos. A blow against Aristotle! Tycho soon decided on a far more ambitious project: to find the diurnal parallax of Mars. $\mathrm{He}$ believed that, in the Ptolemaic system, Mars at closest approach would be roughly 20 times

Albert Curtz's compilation of all observations to 1633 . The lion's share, from Tycho, comprise the middle block.

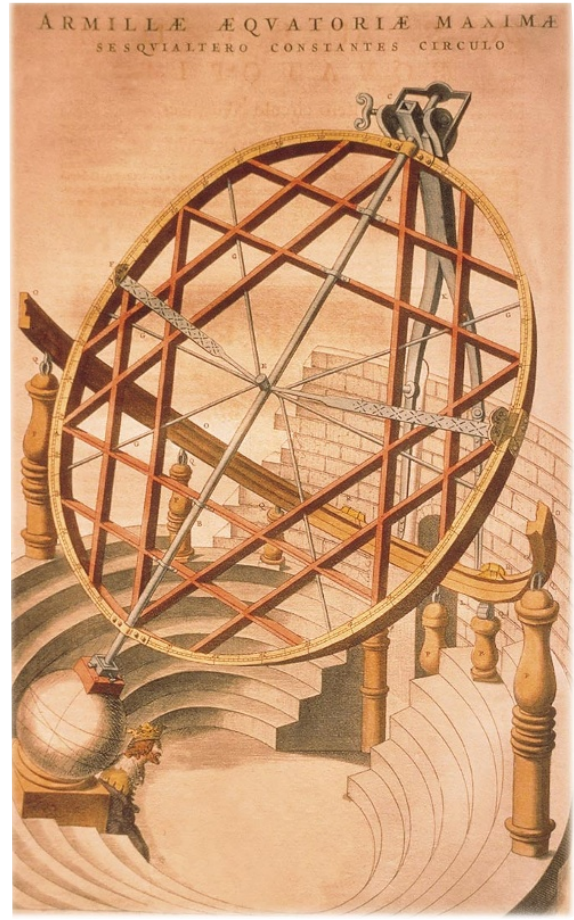

The 1585 equatorial armillary, the most versatile and impressive instrument on Hven.

farther than the Moon. But if the Copernican system held, it would be only about ten times farther, making for an easy measurement of around 5 arcmin. Tycho set out to measure this parallax when Mars passed close to the Earth in the winter of 1582-83.

What Tycho did not know was that every astronomer since antiquity had underestimated the distance to the Sun by a factor of 20. This means that the parallax of Mars is actually around 20 arcsec, well below the resolution of the naked eye. Not surprisingly, Tycho at first found no evidence of the parallax. However, he did not give up, trying again in 1585. The results were disconcerting: Mars seemed to have a negative parallax, placing it beyond infinity, clearly an absurdity. Something was wrong, and Tycho soon identified the culprit. Atmospheric refraction had distorted the planet's position.

Meanwhile, Tycho improved his instruments. A subterranean observatory would protect his sextants and quadrants from the wind and allow for more stable mountings. By the 1587 opposition of Mars, the new Stjerneborg Observatory next to his Uraniborg castle was ready. Tycho's results were, by modern standards, astonishing. He claimed he had found the 5-arcmin parallax, and the Ptolemaic system had to be rejected. We know that Tycho couldn't have found a diur-

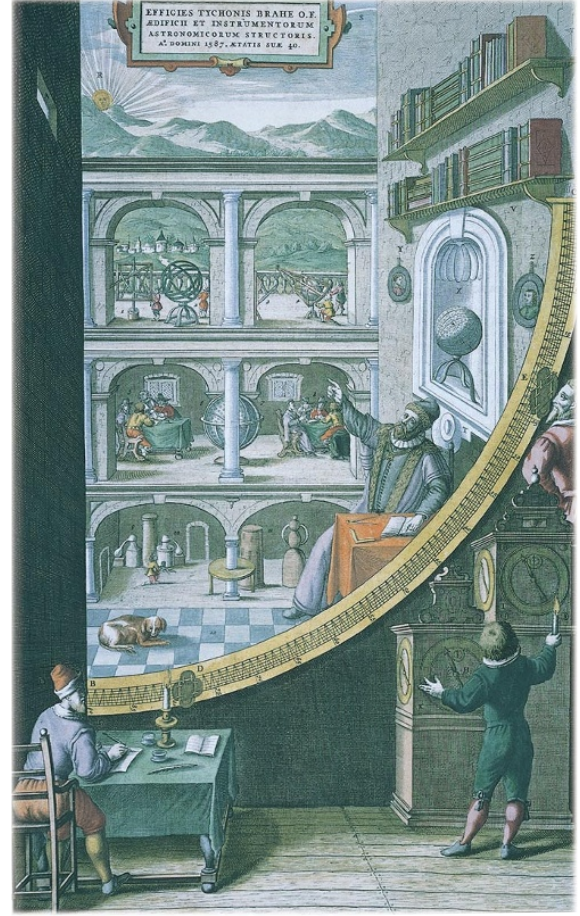

The mural quadrant with scenes from Tycho's scientific establishment at Uraniborg castle.

nal parallax because the Solar System is much bigger than he supposed. Was he lying about a result he yearned so deeply to find?

The problem lay in a faulty table of atmospheric refraction. As a conscientious observer, Tycho tested his table by measuring the refraction for Jupiter. He realized he had used an erroneous refraction table for Mars, and his results disappeared like a puff of smoke. Tycho's brilliantly conceived research programme had collapsed for reasons he could not fathom. Kepler, some years later, found the answer: the Solar System was at least three times larger than anyone had imagined.

In the intervening years, Tycho had moved to Prague, where he died, perhaps poisoned by the mercurial elixirs cooked up in his alchemical laboratory. The emperor procured the observational books for young Kepler, who found in them the goldmine of martian observations he needed to unlock the secrets of planetary astronomy. But this was no accident. They had been made with such marvellous accuracy for a purpose, by the man who defined what observing was all about. If we sing of Tycho, it is probably for the wrong reasons, but he was truly a pioneer who shaped the millennium.

Owen Gingerich is at the Harvard-Smithsonian Center for Astrophysics, 60 Garden Street, Cambridge, Massachusetts 02138, USA. 